Western University Scholarship@Western

1984

\title{
Preferential Trading Agreements: An Investigation
}

Ian Wooton

Follow this and additional works at: https://ir.lib.uwo.ca/economicsresrpt

Part of the Economics Commons

Citation of this paper:

Wooton, Ian. "Preferential Trading Agreements: An Investigation." Department of Economics Research Reports, 8414. London, ON: Department of Economics, University of Western Ontario (1984). 
ISBN：0-7714-0581-2

ISSN : $\quad 0318-725 \mathrm{X}$

\#10417

RESEARCH REPORT 8414

PREFERENTIAL TRADING AGREEMENTS:

AN INVESTIGATION

by ECGNOMCS REFERENCE COUTRE

Ian Wooton MAR -61997

BHWERSITY OF WESTERW OHTAAIO

September, 1984 


\section{INTRODUCTION}

Wuch of the early analysis of preferential trading clubs (PTCs), a general term including free-trade areas and customs unions, was couched in terms of models with three countries (the two partner countries and the rest of the world) and two goods. These $3 \times 2$ models suffer from the drawback that, generally, it is not possible for both members of the club to trade contemporaneously with both their partner and the rest of the world. The trade pattern is asymmetric and formation of the club typically involves a complete reorientation in the pattern of world trade. In the light of this shortcoming there has recently been a growth in the literature on models with three traded commodities. The earliest discussion of such a model was by Meade (1955, Ch. III) which was expanded upon by Munde11 (1964), Vanek (1965, appendix), Ifipsey, Chs. 5 and 6) and McMillan and McCann (1981). In addition, Corden (1976), Berglas (1979), Collier (1979), and Riezman (1979) have analyzed preferential trading agreements in $3 \times 3$ models. This activity has resulted in a multitude of seemingly unrelated results which have, fortunately, been resolved and integrated by Lloyd (1982). Each of these three-commodity models assumes a particular pattern of trade and the derived results are dependent on this assumed trade flow. A model incorporating more goods would be necessary in order to incorporate all of the potential patterns of exchange. McMillan and McCann increase the number of goods traded beyond three but do not increase the complexity of the trading pattern. In an appendix, Berglas (1979) extends his threecommodity model to one in which $\mathbf{n}$ goods are traded while Ethier and Horn (1984) have a model incorporating twelve tradeables. 
Increasing the dimensionality of a model of discriminatory trading rapidiy reduces its tractability and consequently its usefulness. The purpose of this paper is to present a $3 \times n$ model of international trade that has the potential to encompass any trading pattern whatsoever while remaining easily tractable. Specialization in production, a constraint imposed initially by Meade, is relaxed and all countries can both produce and consume all goods. Export subsidies, in addition to import tariffs, are discussed. Two strong assumptions are made (which are shared by Berglas, Meade, Riezman, and others) that: firstly, the formation of a PTC may change the volume, but not the existing pattern of international trade; and secondly, that all countries consume all goods, though they need not trade in all goods.

The remainder of the paper is as follows. In Part 2, the general structure of the model, using the dual approach to international trade of Dixit and Norman (1980), is introduced. The formation of a PTC by its members reducing their duties on trade with one another is discussed in Section 3. Section 4 examines the conditions under which "small" countries will benefit from making such an arrangement. The optimal taxes on intra-club trade are also determined. Intra-union terms of trade effects are studied in Section 5 , in which "local goods", traded only between partner countries, are introduced. 2 Section 6 briefly considers a PTC composed of "large" countries and the consequent changes in the international terms of trade. The paper ends with a summary and conclusions. 
2. THE GENERAL MODEL

There are three countries in the world, A, B, and $C$, each consisting of a single household. ${ }^{3}$ Each country has an arbitrary number of factors of production, all in fixed supply. There are $\mathrm{n}$ commodities produced in the world economy and all are consumed in each country. Each country either exports a particular good to or imports it from one or both of the other countries.

In addition, it is assumed that there is no "cross-hauling", that is, no country exports a particular good to one country and imports the same good from the other. Given these assumptions, six patterns of trade in any particular good are possible--in each case one of the countries trades with the two others, either exporting the good to both or importing it from both. The trade patterns are represented as: $B-A-C ; A-B-C$; and $A-C-B--w h e r e$ the central country trades with the other two. Distinction between a country's export goods and its import goods will be made where necessary.

In the initial trading equilibrium, each country has imposed a tax-cum-subsidy structure on its international trade. An import tariff on a good raises its domestic price above the international price while a tax on an export lowers that good's domestic price relative to its international price. The equilibrium may be represented as:

$$
\begin{aligned}
& e^{a}\left(p^{a}, u^{a}\right)=r^{a}\left(p^{a}, v^{a}\right)+t^{a} \cdot m^{a} \\
& e^{b}\left(p^{b}, u^{b}\right)=r^{b}\left(p^{b}, v^{b}\right)+t^{b} \cdot m^{b} \\
& e^{c}\left(p^{c}, u^{c}\right)=r^{c}\left(p^{c}, v^{c}\right)+t^{c} \cdot m^{c}
\end{aligned}
$$

where $e^{j}\left(p^{j}, u^{j}\right)$ is the minimum expenditure necessary by country $J$ to achieve 
utility $u^{j}$ when the vector of domestic prices of $n$ goods is $p^{j} ; r^{j}\left(p^{j}, v^{j}\right)$ is the maximum attainable revenue at the same domestic prices, given the fixed vector of factor supplies, $v^{j}$; and $t^{j} \cdot \mathrm{m}^{\mathbf{j}}$ is the total of tax revenues on international trade, $t^{j}$ being the vector of specific import tariffs (positive terms) and export taxes (negative terms) and $\mathrm{m}^{\mathrm{j}}$ being the vector of net imports of the $n$ goods. Output supply and consumption demand for goods are obtained by differentiating with respect to price the revenue function and the expenditure function respectively. Import demand for a particular good is the difference between its domestic demand and domestic supply:

$$
m^{j}=e_{p}^{j}-r_{p}^{j} \text { for } j=a, b, c \text {. }
$$

In equilibrium, international excess demand for each good must be zero:

$$
e_{p}^{a}+e_{p}^{b}+e_{p}^{c}-r_{p}^{a}-r_{p}^{b}-r_{p}^{c}=0
$$

That is,

$$
m^{a}+m^{b}+m^{c}=0 \text {. }
$$

The domestic price of each good is distorted from the international price, $p^{e}$, by the amount of the trade tax

$$
p^{j}=p^{e}+t^{j} \text { for } j=a, b, c \text {. }
$$

\section{PREFERENTIAL TRADING CLUB}

Let countries A and B form a preferential trading club (PTC) by marginally lowering duties on bilateral trade, such that the pattern of trade is not disturbed. If such taxes were entirely eliminated $A$ and $B$ would constitute a Free Trade Area (FTA). If their taxes on trade with C 
were also to be equalized this would result in a Customs Union (CU).$^{4}$. Some discrimination mist now be made between a country's sources of imports and between the destinations of its exports, as the tax revenues will be lower for trade with its partner. The national income-expenditure relations become

$$
\begin{aligned}
& e^{a}\left(p^{a}, u^{a}\right)=r^{a}\left(p^{a}, v^{a}\right)+t^{a i} \cdot m^{a b}+t^{a e} \cdot m^{a c} \\
& e^{b}\left(p^{b}, u^{b}\right)=r^{b}\left(p^{b}, v^{b}\right)+t^{b i} \cdot m^{b a}+t^{b e} \cdot m^{b c} \\
& e^{c}\left(p^{c}, u^{c}\right)=r^{c}\left(p^{c}, v^{c}\right)+t^{c} \cdot m^{c}
\end{aligned}
$$

where the superscripted $i$ and e refer to intra-club and extra-club respectively and $\mathrm{m}^{\mathrm{jk}}$ is the net imports of country $\mathrm{J}$ from country $\mathrm{K}$. Thus

$$
\begin{aligned}
& \mathrm{m}^{\mathrm{ab}}+\mathrm{m}^{\mathrm{ac}}=\mathrm{m}^{\mathrm{a}} \\
& \mathrm{m}^{\mathrm{ba}}+\mathrm{m}^{\mathrm{bc}}=\mathrm{m}^{\mathrm{b}}
\end{aligned}
$$

Note that $\mathrm{m}^{\mathrm{ab}}=-\mathrm{m}^{\mathrm{ba}}$

and thus $\mathrm{m}^{\mathrm{ac}}+\mathrm{m}^{\mathrm{bc}}=-\mathrm{m}^{c}$.

Countries trading with one another must do so at the same international terms of trade. Thus if good $X$ is traded between $A$ and $B$, in the club, then

$$
p_{x}^{a}-t_{x}^{a i}=p_{x}^{b}-t_{x}^{b i}=p_{x}^{i}
$$

where $p_{x}^{i}$ is the intra-club price of good $x$. Cross-hauling of goods does not occur and so only one of $A$ and $B$ trades with $C$ when there is also intra-club trade.

$$
p_{x}^{j}-t_{x}^{j e}=p_{x}^{c}-t^{c}=p_{x}^{e} \text { for } j=\text { either } a \text { or } b
$$

If, before the formation of the club, $A$ and $B$ do not trade with one another in a particular good, then a marginal reduction of impediments to 
trade between them will have no effect. ${ }^{5}$ The preferential trading club is therefore formed by the reduction of trade taxes on goods for which $\mathrm{m}_{\mathrm{x}}^{\mathrm{ab}} \neq 0$.

Total differentiation of the equilibrium conditions $(5,6,7$, and 8 )

results in:

$$
\begin{aligned}
& e_{p}^{a} \cdot d p^{a}+e_{u^{a} d u^{a}}^{a}=r_{p}^{a} \cdot d p^{a}+t^{a i} \cdot d m^{a b}+t^{a e} \cdot d m^{a c}+m^{a b} \cdot d t^{a i} \\
& e_{p}^{b} \cdot d p^{b}+e_{u^{b} d u^{b}}^{b}=r_{p}^{b} \cdot d p^{b}+t^{b i} \cdot d m^{b a}+t^{b e} \cdot d m^{b c}+m^{b a} \cdot d t^{b i} \\
& e_{p}^{c} \cdot d p^{c}+e_{u^{c}}^{c} u^{c}=r_{p}^{c} \cdot d p^{c}+t^{c} \cdot d m^{c} \\
& e_{p p}^{a} d p^{a}+e_{p u^{d}}^{a} d u^{a}+e_{p p}^{b} d p^{b}+e_{p u^{b}}^{d b}+e_{p p}^{c} d p^{c}+e_{p u}^{c} d u^{c} \\
& -r_{p p}^{a} d p^{a}-r_{p p}^{b} d p^{b}-r_{p p}^{c} d p^{c}=0 .
\end{aligned}
$$

Let $s^{j}=e_{p p}^{j}-r_{p p}^{j}$, for $j=a, b, c$, the matrices of derivatives of the countries' compensated excess demands for goods with respect to prices. The world matrix is $s=s^{a}+s^{b}+s^{c}$. These matrices are negative semi-definite. With the assumption that expenditure and revenue functions are linearly homogeneous,

$$
\mathbf{s}^{\mathbf{j}} \mathbf{p}^{\mathbf{j}}=0, \text { for } \mathbf{j}=a, b, c \text {. }
$$

Substituting these and equation (4) yields

$$
\begin{aligned}
& m^{a} \cdot d p^{a}+e_{u}^{a} d u^{a}=t^{a i} \cdot d m^{a b}+t^{a e} \cdot d m^{a c}+m^{a b} \cdot d t^{a i} \\
& m^{b} \cdot d p^{b}+e_{u}^{b} d u^{b}=t^{b i} \cdot d m^{b a}+t^{b e} \cdot d m^{b c}+m^{b a} \cdot d t^{b i} \\
& m^{c} \cdot d p^{c}+e_{u}^{c} d u^{c}=t^{c} \cdot d m^{c} \\
& s^{a} d p^{a}+s^{b} d p^{b}+s^{c} d p^{c}+e_{p u}^{a} d u^{a}+e_{p u}^{b} d u^{b}+e_{p u}^{c} d u^{c}=0
\end{aligned}
$$

How are domestic price changes related to one another? This depends on the pattern of trade for each good. Suppose good X is traded according 
to pattern $B-A-C$. In this case, $A^{\prime} s$ domestic price of those $X$ produced in or exported to $B$ must be equal to $A$ 's domestic price of those $X$ traded with C. That is

$$
p_{x}^{a}=p_{x}^{e}+t_{x}^{a e}=p_{x}^{i}+t_{x}^{a i}
$$

Now $\quad p_{x}^{c}=p_{x}^{e}+t_{x}^{c}$ and $p_{x}^{b}=p_{x}^{i}+t_{x}^{b i}$.

Differentiating, setting $d t_{X}^{a e}=0$ (as the extra-club tariff is to be unchanged),

$$
\begin{aligned}
& d p_{x}^{a}=d p_{x}^{e}=d p_{x}^{i}+d t_{x}^{a i} \\
& d p_{x}^{c}=d p_{x}^{e} \\
& d p_{x}^{b}=d p_{x}^{i}+d t_{x}^{b i} .
\end{aligned}
$$

Thus $\quad d p_{x}^{a}=d p_{x}^{c}=d p_{x}^{b}+\Delta_{x}=d p_{x}^{e}$

where $\quad \Delta_{x}=d t_{x}^{a i}-d t_{x}^{b i}$.

Similarly, for trade pattern A-B-C,

$$
d p_{x}^{b}=d p_{x}^{c}=d p_{x}^{a}-\Delta_{x}=d p_{x}^{e} .
$$

This may be summarized for all goods as

$$
\begin{aligned}
& d p^{a}=d p^{e}+\Delta^{a} \\
& d p^{b}=d p^{e}-\Delta^{b}
\end{aligned}
$$

where $\quad \Delta_{x}^{a}= \begin{cases}\Delta_{x}, & \text { for trade pattern } A-B-C \\ 0, & \text { otherwise }\end{cases}$

$$
\begin{aligned}
& \Delta_{x}^{b}= \begin{cases}\Delta_{x}, & \text { for trade pattern B-A-C } \\
0, & \text { otherwise }\end{cases} \\
& \Delta^{a}+\Delta^{b}=\Delta=\mathrm{dt}^{a i}-\mathrm{dt}^{\mathrm{bi}} .
\end{aligned}
$$

$\Delta$ measures the reduction in the divergence between the partner countries' domestic prices,

$$
\Delta=d p^{a i}-d p^{b i} .
$$


Whenever $A$ or $B$ trades with $C$, the change in the domestic price of that good is tied to the change in the extra-club price. Thus

$$
\begin{aligned}
& m^{a c} \cdot d p^{a}=m^{a c} \cdot d p^{e} \\
& m^{b c} \cdot d p^{b}=m^{b c} \cdot d p^{e}
\end{aligned}
$$

However, $m^{a b} \cdot d p^{a}=m^{a b} \cdot\left(d p^{e}+\Delta^{a}\right)$

$$
m^{b a} \cdot d p^{b}=m^{b a} \cdot\left(d p^{e}-\Delta^{b}\right)
$$

Rewriting (11),

$$
\begin{aligned}
& m^{a} \cdot d p^{e}+m^{a b} \cdot \Delta^{a}+e_{u^{a}}^{a} u^{a}=t^{a i} \cdot d m^{a b}+t^{a e} \cdot d m^{a c}+m^{a b} \cdot d t^{a i} \\
& m^{b} \cdot d p^{e}-m^{b a} \cdot \Delta^{b}+e_{u}^{b} d u^{b}=t^{b i} \cdot d m^{b a}+t^{b e} \cdot d m^{b c}+m^{b a} \cdot d t^{b i} \\
& \quad m^{c} \cdot d p^{e} \quad+e_{u^{c}}^{c} u^{c}=t^{c} \cdot d m^{c} \\
& \text { Let } d r=d t^{a i}-\Delta^{a}=d t^{b i}+\Delta^{b}
\end{aligned}
$$

where

$$
d T_{x}= \begin{cases}d t_{x}^{b i}, & \text { for trade pattern } A-B-C \\ d t_{x}^{a i}, & \text { for trade pattern } B-A-C \\ 0, & \text { for trade pattern } A-C-B\end{cases}
$$

dT measures the shift of intra-club prices from extra-club prices,

$$
d T=d p^{e}-d p^{i}
$$

Substitute this, together with the initial non-discriminatory tariffs,

$$
\begin{aligned}
t^{a i} & =t^{a e}=t^{a} \\
\text { and } \quad t^{b i} & =t^{b e}=t^{b},
\end{aligned}
$$

to obtain 


$$
\left.\begin{array}{l}
m^{a} \cdot d p^{e}+e_{u}^{a} d u^{a}=t^{a} \cdot d m^{a}+m^{a b} \cdot d T \\
m^{b} \cdot d p^{e}+e_{u}^{b} d u^{b}=t^{b} \cdot d m^{b}+m^{b a} \cdot d T \\
m^{c} \cdot d p^{e}+e_{u}^{c} d u^{c}=t^{c} \cdot d m^{c}
\end{array}\right\}
$$

Summing across theseriaquations yields

$$
e_{u}^{a} d u^{a}+e_{u}^{b} d u^{b}+e_{u}^{c} d u^{c}=t^{a} \cdot d m^{a}+t^{b} \cdot d m^{b}+t^{c} \cdot d m^{c},
$$

world welfare depends solely on the volume of trade.

Recalling equation (4) and differentiating

$$
d m^{j}=e_{p p}^{j} d p^{j}-r_{p p}^{j} d p^{j}+e_{p u}^{j} d u^{j}, \text { for } j=a, b, c \text {. }
$$

Rewriting, letting $e_{p u}^{j}=c_{y}^{j} e_{u}^{j}$ where $c_{y}^{j}$ is the vector of marginal propensities to consume each good in country $J$, then

$$
d m^{j}=s^{j} d p^{j}+c y_{y}^{j} e^{j} d u^{j}
$$

Substituting this, and equations (13) and (14), into (12) and (15):

$$
\begin{aligned}
& \left(m^{a^{\prime}}-t^{a^{\prime}} s^{a}\right) d p^{e}+\left(1-t^{a} \cdot c_{y}^{a}\right) e_{u}^{a} d u^{a}=t^{a^{\prime}} s^{a} \Delta^{a}+m^{a b} \cdot d T \\
& \left.\left(m^{b^{\prime}}-t^{b^{\prime}} s^{b}\right) d p^{e}+\left(1-t^{b} \cdot c_{y}^{b}\right) e_{u}^{b} d u^{b}=-t^{b^{\prime}} s^{b} \Delta^{b}+m^{b a} \cdot d T\right\} \\
& \left(m^{c^{\prime}}-t^{c^{\prime}} s^{c}\right) d p^{e}+\left(1-t^{c} \cdot c_{y}^{c}\right) e_{u}^{c} d u^{c}=0 \\
& S d p^{e}+c_{y}^{a} e_{u}^{a} d u^{a}+c{ }_{y}^{b} e_{u}^{b} d u^{b}+c_{y}^{c} e_{u}^{c} d u^{c}=s^{b} \Delta^{b}-s^{a} \Delta^{a}
\end{aligned}
$$

\section{A AND B AS "SMALL" COUNTRIES}

Suppose the economy of country $C$ is sufficiently large relative to those of $A$ and $B$ that changes in intra-club tariffs would have no effect on either the domestic prices of $C$ or the extra-club international prices, i.e. $d p^{e}=0$. In such a case, the relations of (16) reduce to 


$$
\begin{aligned}
& \left(1-t^{a} \cdot c_{y}^{a}\right) e_{u}^{a} d u^{a}=t^{a^{\prime}} s^{a} \Delta^{a}+m^{a b} \cdot d T \\
& \left(1-t^{b} \cdot c_{y}^{b}\right) e_{u}^{b} d u^{b}=-t^{b^{\prime}} s^{b} \Delta^{b}+m^{b a} \cdot d T \\
& \left(1-t^{c} \cdot c_{y}^{c}\right) e_{u}^{c} d u^{c}=0
\end{aligned}
$$

The welfare of country $C$ is unaffected by intra-club behavior. Rewriting,

$$
\left.\begin{array}{l}
d u^{a}=\frac{1}{\left(1-t^{a} \cdot c_{y}^{a}\right) e_{u}^{a}}\left\{t^{a^{\prime}} s^{a} \Delta^{a}+m^{a b} \cdot d T\right\} \\
d u^{b}=\frac{1}{\left(1-t^{b} \cdot c_{y}^{b}\right) e_{u}^{b}}\left\{-t^{b^{\prime}} s^{b} \Delta^{b}+m^{b a} \cdot d T\right\}
\end{array}\right\}
$$

Consider the welfare impact on country A of the formation of a preferential trading club. Changes in intra-club tariffs will have different consequences dependent on the pattern of trade.

Let the trade pattern for good $X$ be B-A-C. Then $\Delta_{x}^{a}=0$. Country A continues to trade in $X$ with country $C$, but neither has there been a change in extra-union prices nor has $A$ changed its extra-union taxes. Thus A's domestic price for $\mathrm{X}$ is unaltered. A has, however, lowered its barriers on trade in $\mathrm{X}$ with $\mathrm{B}$, offering it improved terms of trade. A has therefore "diverted" ${ }^{6}$ its trading in $X$ from $C$ to $B$, the higher-price supplier (or, in the case of exports of X from $A$, the lower-price buyer). No benefit comes to A from an improvement in its terms of trade, yet it suffers the loss of tariff revenues, $\mathrm{m}_{\mathrm{x}}^{\mathrm{ab}} \mathrm{dt}{ }^{\mathrm{ai}}$.

Let the pattern of trade in good $X$ be $A-B-C$ instead. $B$ now has its domestic prices fixed and so its reduction in the intra-club taxes will 
improve $A^{\prime}$ 's terms of trade, as will $A^{\prime} s$ own tax reduction. For example, if $X$ is imported by $A$, then $d t_{x}^{a i}<0, d t_{x}^{b i}>0$ (A lowers its tariff, $B$ lowers its export tax) and so $\Delta_{x}^{a}=d t_{x}^{a i}-d t_{x}^{b i}<0$. Whether $A$ benefits from this depends on the sign of $t^{a^{\prime}} s^{a} \Delta_{x}^{a}$. The total effect on the welfare of $A$ through changes in the terms of trade as a result of a preferential trading agreement depends on $t^{a^{\prime}} s^{a} \Delta^{a}$. This is discussed in the appendix, the condition for welfare improvement from the change in $A^{\prime}$ s terms of trade for these goods being

(i) the imported goods must be substitutes for A's exports;

(ii) the exported goods must be substitutes for $A^{\prime}$ 's imports.

These conditions are closely related to, but more general than, those derived by McMillan and McCann. With output being fixed in their model, substitutability in consumption was necessary for welfare improvement. When production is variable, it may be a source of substitution that compensates for any complementarity in consumption.

A will additionally benefit by $m_{x}^{a b} d t_{x}^{b i}$ from being paid a higher price for existing trade between the two countries. Note that this gain is exactly equal to the loss in tariff revenue for $B$ due to trade diversion.

It is clear that the formation of a preferential trading agreement with respect to a particular good will result (given the condition of sufficient substitutability) in a gain to one country and a loss to the other member of the club. However the loser can be exactly compensated for his lost revenue by the other, which still retains all the terms of trade gain. Thus the club formation, with compensation, is welfare improving. 
Summing across (18)

$$
\left(1-t^{a} \cdot c_{y}^{a}\right) e_{u}^{a} d u^{a}+\left(1-t^{b} \cdot c_{y}^{b}\right) e_{u}^{b} d u^{b}=t^{a^{\prime}} s^{a} \Delta^{a}-t^{b^{\prime}} s^{b} \Delta^{b}>0,
$$

with the substitutability condition fulfilled. The net benefit to the club is from the improvement in domestic terms of trade.

Clearly the optimal trade policy for each of the two small countries would be the elimination of all trade taxes, both intra-club and extra-club. Suppose, however, that extra-club taxes were to be maintained at their present non-zero level. 8 What then would be the optimal rates of intra-club taxes on trade? In Appendix 2, an experiment is conducted to determine $A^{\prime} s$ optimal tariff on imports. It is demonstrated that this tariff should be proportionately less than other tariffs, but need not be zero. Thus, as would be expected, the second-best optimum tariff ${ }^{9}$ in the face of other distortions differs from the first-best (zero) tariff. 10

5. IOCAL GOODS

Suppose that, prior to and after the formation of a preferential trading club, there are some goods ${ }^{11}$ which $A$ and $B$ do not trade with $C$. These "local goods" may be traded between the geographically-close countries A and B, but, say due to transport costs, may not be traded with $C$. Let goods which are traded between all three countries be termed "world goods". The assumption of $A$ and $B$ being "small" relative to $C$ is maintained for goods that are traded between all three. However $C$ does not trade in local goods and so their prices mast be determined endogenously. Let the domestic prices of local goods be $q^{j}($ for $j=a, b, c)$. National income-expenditure relations are 


$$
\begin{aligned}
& e^{a}\left(p^{a}, q^{a}, u^{a}\right)=r^{a}\left(p^{a}, q^{a}, v^{a}\right)+t^{a i} \cdot m^{a b}+t^{a e} \cdot m^{a c}+\tilde{t}^{a} \cdot \tilde{m}^{a} \\
& e^{b}\left(p^{b}, q^{b}, u^{b}\right)=r^{b}\left(p^{b}, q^{b}, v^{b}\right)+t^{b i} \cdot m^{b a}+t^{b e} \cdot m^{b c}+\tilde{t}^{b} \cdot \tilde{m}^{b} \\
& e^{c}\left(p^{c}, q^{c}, u^{c}\right)=r^{c}\left(p^{c}, q^{c}, v^{c}\right)+t^{c} \cdot m^{c}
\end{aligned}
$$

where $\tilde{t}^{j}$ and $\tilde{m}^{j}$ are the trade levies and the net imports, respectively, of local goods. The market-clearing conditions are:

$$
\begin{aligned}
& e_{p}^{a}+e_{p}^{b}+e_{p}^{c}-r_{p}^{a}-r_{p}^{b}-r_{p}^{c}=0 \\
& e_{q}^{a}+e_{q}^{b}-r_{q}^{a}-r_{q}^{b}=0 \\
& e_{q}^{c}-r_{q}^{c}=0
\end{aligned}
$$

Equation (22) may be rewritten as :

$$
\tilde{\mathrm{m}}^{\mathrm{a}}+\tilde{\mathrm{m}}^{\mathrm{b}}=0 \text {, }
$$

while country $C$ does not trade in local goods and hence its domestic supply must satisfy domestic demand [i.e., $\widetilde{m}^{c}=0$ ]. The domestic prices of local goods in $A$ and $B$ are related by the following expression:

$$
q^{a}-\tilde{t}^{a}=q^{b}-\tilde{t}^{b}=q^{i}
$$

Differentiating (20) and (25), assuming initially that trade taxes are non-discriminatory, and substituting,

$$
\begin{aligned}
& \mathrm{m}^{a} \cdot d p^{e}+\tilde{m}^{a} \cdot d q^{i}+e_{u}^{a} d u^{a}=t^{a} \cdot d m^{a}+\tilde{t}^{a} \cdot d \tilde{m}^{a}+m^{a b} \cdot d T \\
& m^{b} \cdot d p^{e}+\tilde{m}^{b} \cdot d q^{i}+e_{u}^{b} d u^{b}=t^{b} \cdot d m^{b}+\tilde{t}^{b} \cdot d \tilde{m}^{b}+m^{b a} \cdot d T \\
& \mathrm{~m}^{c} \cdot \mathrm{dp}^{\mathrm{e}} \quad+\mathrm{e}_{\mathrm{u}}^{c} \mathrm{du}^{c}=\mathrm{t}^{c} \cdot \mathrm{dm}^{c}
\end{aligned}
$$

Summing across these equations yields once more the result that changes in world welfare depend on the changes in the volume of trade,

$$
e_{u}^{a} d u^{a}+e_{u}^{b} d u^{b}+e_{u}^{c} d u^{c}=t^{a} \cdot d m^{a}+t^{b} \cdot d m^{b}+t^{c} \cdot d m^{c}+\tilde{t}^{a} \cdot d \tilde{m}^{a}+\tilde{t}^{b} \cdot d \tilde{m}^{b}
$$

Changes in country A's imports are: 
$d\left[\begin{array}{l}m^{a} \\ r^{a}\end{array}\right]=d\left[\begin{array}{c}e_{p}^{a}-r_{p}^{a} \\ e_{q^{a}}^{a}-r_{q}^{a}\end{array}\right]=\left[\begin{array}{cc}\left(e_{p p}^{a}-r_{p p}^{a}\right) & \left(e_{p q^{a}}^{-r_{p q}^{a}}\right) \\ \left(e_{q p}^{a}-r_{q p}^{a}\right) & \left(e_{q q^{a}}^{-r_{q q}^{a}}\right)\end{array}\right]\left[\begin{array}{l}d p^{a} \\ d q^{a}\end{array}\right]+\left[\begin{array}{l}e_{p u}^{a} \\ e_{q u}^{a}\end{array}\right] d u^{a}$

$$
\begin{aligned}
& =\left[\begin{array}{cc}
s^{a} & f^{a} \\
f^{a^{\prime}} & \hat{s}^{a}
\end{array}\right]\left[\begin{array}{l}
d p^{e}+\Delta^{a} \\
d q^{i}+d \hat{t}^{a}
\end{array}\right]+\left[\begin{array}{l}
e_{p u}^{a} \\
e_{q u}^{a}
\end{array}\right] d u^{a} \\
& =\bar{s}^{a}\left[\begin{array}{l}
d p^{e} \\
d q^{i}
\end{array}\right]+s^{-a}\left[\begin{array}{l}
\Delta^{a} \\
d \hat{t}^{a}
\end{array}\right]+\left[\begin{array}{l}
c_{y}^{a} \\
c_{y}^{a}
\end{array}\right] e_{u}^{a} d u^{a}
\end{aligned}
$$

where the definitions of $f^{a}, \tilde{s}^{a}, \vec{s}^{-a}, \widetilde{c}_{y}^{a}$ are obvious. Similarly for country B :

$a\left[\begin{array}{c}m^{b} \\ \tilde{m}^{b}\end{array}\right]=-s^{b}\left[\begin{array}{c}d p^{e} \\ d q^{i}\end{array}\right]+s^{-b}\left[\begin{array}{c}-\Delta^{b} \\ d \tilde{t}^{b}\end{array}\right]+\left[\begin{array}{c}c b \\ y \\ \tilde{c}_{y}^{b}\end{array}\right] e_{u}^{b} d u^{b}$

Let $\bar{m}^{-j}=\left[\begin{array}{c}m^{j} \\ \sim_{m}^{j}\end{array}\right], \bar{t}^{j}=\left[\begin{array}{c}t^{j} \\ \tilde{t}^{j}\end{array}\right]$ and $\bar{c}_{y}^{j}=\left[\begin{array}{c}c^{j} \\ y \\ \tilde{c}_{y}^{j} \\ y\end{array}\right]$ for $j=a, b$ and substitute (29) and (30) into

(26) and (27):

$$
\begin{aligned}
& \left(\mathrm{m}^{a^{\prime}}-\bar{t}^{\left.-a^{\prime}-\bar{s}^{a}\right)}\left[\begin{array}{l}
d p^{e} \\
d q^{i}
\end{array}\right]+\left(1-\bar{t}^{a} \cdot \bar{c} y^{a}\right) e_{u}^{a} d u^{a}=\bar{t}^{a^{\prime}-a}\left[\begin{array}{l}
\Delta^{a} \\
d \tilde{t}^{a}
\end{array}\right]+m^{a b} \cdot d T\right. \\
& \left(\bar{m}^{b^{\prime}}-\bar{t}^{-b^{\prime}-b}\left[\begin{array}{l}
d p^{e} \\
d q^{i}
\end{array}\right]+\left(1-\bar{t}^{b} \cdot \bar{c} y^{b}\right) e_{u}^{b} d u^{b}=\bar{t}^{-b^{\prime}-b}\left[\begin{array}{l}
-\Delta^{b} \\
\left.d \tilde{t}^{b}\right]+m^{b a} \cdot d T
\end{array}\right.\right.
\end{aligned}
$$

Consider now the formation of a preferential trading club between the two small (i.e., $\mathrm{dp}^{\mathrm{e}}=0$ ) countries $\mathrm{A}$ and $\mathrm{B}$. 


$$
\begin{aligned}
& \left(1-\bar{t}^{a} \cdot \bar{c}_{y}^{-a}\right) e_{u}^{a} d u^{a}=\bar{t}^{-a^{\prime}} \cdot-a\left[\begin{array}{c}
\Delta^{a} \\
d q^{i}+d \tilde{t}^{a}
\end{array}\right]+m^{a b} \cdot d T-\tilde{m}^{a} \cdot d q^{i} \\
& \left(1-\bar{t}^{-b} \cdot c_{y}^{-b}\right) e_{u}^{b} d u^{b}=\bar{t}^{b^{\prime}}-b\left[\begin{array}{c}
-\Delta^{b} \\
d q^{i}+d \tilde{t}^{b}
\end{array}\right]+m^{b a} \cdot d T-\tilde{m}^{b} \cdot d q^{i}
\end{aligned}
$$

The last two terms of each equation represent the initial volume of imports from the partner country times the shift in intra-club prices as a result of the tax changes, while the preceding bracketed term is the vector of changes in each country's domestic prices. ${ }^{12}$ Combining equations (33) and (34), to obtain the overall welfare effect of forming the club, yields

$$
\left(1-\bar{t}^{-a} \cdot c_{y}^{-a}\right) e_{u}^{a} d u^{a}+\left(1-\bar{t}^{b} \cdot c_{y}^{-b}\right) e_{u}^{b} d u^{b}=t^{-a-a}\left[\begin{array}{c}
\Delta^{a} \\
d q^{i}+d \tilde{t}^{-a}
\end{array}\right]+\bar{t}^{b^{\prime}-b}\left[\begin{array}{c}
\Delta^{b} \\
d q^{i}+d \tilde{t}^{b}
\end{array}\right]
$$

Gains made by one country through being paid higher prices for its existing exports, or paying lower prices for its existing imports, are offset by the losses endured by its partner. Thus the net impact on the two countries together of the trade liberalization is due solely to the changes in their domestic terms of trade.

In Section 4, conditions were stated for the formation of the PTC to be welfare-improving for the two partner countries. These conditions also hold in this instance, when local goods have been incorporated into the analysis, with one important proviso. The intra-club prices of local goods are endogenously determined and any changes in these will benefit one country at the expense of the other. Sufficiently large variations in the local terms of trade might result in a welfare loss to a country from the formation of the PTC, even when compensation for trade diversion losses has been made. 


\section{A AND B AS "IARGE" COUNTRIES}

Suppose that the changes in production and consumption induced by the formation of the preferential trading club affect both the domestic prices of $\mathrm{C}$ and the extra-club international price structure. The impact of changes in the terms of trade may be determined by substituting equation (17) into the equations of (16):

$$
M\left[\begin{array}{c}
e_{u}^{a} d u^{a} \\
e_{u}^{b} d u^{b} \\
e_{u}^{c} d u^{c}
\end{array}\right]=\left[\begin{array}{c}
t^{a^{\prime}} s^{a} \Delta^{a}+m^{a b} d T \\
-t^{b^{\prime}} s^{b} \Delta^{b}+m^{b a} d T \\
0
\end{array}\right]+\left[\begin{array}{c}
B^{a} \\
B b \\
B^{c}
\end{array}\right]\left(s^{b} \Delta^{b}-s^{a} \Delta^{a}\right)
$$

where

$$
M=\left[\begin{array}{ccc}
A^{a} & B^{a} c_{y}^{b} & B^{a} c_{y}^{c} \\
B^{b} c_{y}^{a} & A^{b} & B^{b} c_{y}^{c} \\
B^{c} c_{y}^{a} & B^{c} c_{y}^{b} & A^{c}
\end{array}\right]
$$

and

$$
{ }_{B}^{j}=\left(t^{j^{\prime}} s^{j}-m^{j^{\prime}}\right) s^{-1} \quad, \quad \text { for } j=a, b, c
$$

$$
A^{j}=\left(1-t^{j} \cdot c_{y}^{j}\right)+B^{j} c_{y}^{j} \quad, \quad \text { for } j=a, b, c
$$

$$
\text { Solving, } \begin{aligned}
{\left[\begin{array}{ll}
e_{u}^{a} & d u^{a} \\
e_{u}^{b} & d u^{b} \\
e_{u}^{c} & d u^{c}
\end{array}\right] } & =\frac{1}{D}\left[\begin{array}{cc}
\alpha_{11} & \alpha_{21} \\
\alpha_{12} & \alpha_{22} \\
\alpha_{13} & \alpha_{23}
\end{array}\right]\left[\begin{array}{c}
t^{a^{\prime}} s^{a} \Delta^{a} \\
t^{b^{\prime}} s^{b} \Delta^{b} \\
0
\end{array}\right] \\
+ & \frac{1}{D}\left[\begin{array}{cc}
\alpha_{71} & -\alpha_{21} \\
\alpha_{12} & -\alpha_{22} \\
\alpha_{13} & -\alpha_{23}
\end{array}\right] m^{a b} \cdot d T \\
+ & \frac{1}{D}\left[\begin{array}{ccc}
\alpha_{11} & \alpha_{21} & \alpha_{31} \\
\alpha_{72} & \alpha_{22} & \alpha_{32} \\
\alpha_{73} & \alpha_{23} & \alpha_{33}
\end{array}\right]\left[\begin{array}{c}
B^{a} \\
B^{b}
\end{array}\right]\left(s^{b} \Delta^{b}-s^{a} \Delta^{a}\right),
\end{aligned}
$$


where the $\alpha_{i j}$ are the cofactors of the elements of $M$, and $D$ is its determinant. Consider the welfare impact on A of the formation of the club

$$
\begin{aligned}
e_{u}^{a} d u^{a} & =\frac{1}{D}\left[\alpha_{11} t^{a^{\prime}} s^{a} \Delta^{a}-\alpha_{21} t^{b^{\prime}} s^{b} \Delta^{b}\right]+\frac{1}{D}\left(\alpha_{11}-\alpha_{21}\right) m^{a b} \cdot d T \\
& +\frac{1}{D}\left[\alpha_{11} B^{a}+\alpha_{21} B^{b}+\alpha_{31} B^{c}\right]\left[s^{b} \Delta^{b}-s^{a} \Delta^{a}\right]
\end{aligned}
$$

The first term is the "large-country" analogue to the Intra-club terms of trade gain from PIC formation. It was shown previously that, with assumptions of substitutability,

$$
t^{a^{\prime}} s^{a} \Delta^{a}>0, t^{b^{\prime}} s^{b} \Delta^{b}<0
$$

Thus, if $\alpha_{11} / D$ and $\alpha_{21} / D$ are positive, country A gains both from its own trade liberalization and that of its partner for trade pattern A-B-C.

The second term's sign depends upon the trade pattern. For B-A-C, $A$ is lowering duties on trade with only one of the countries with which it trades a particular good and thereby loses tax revenues. This has been termed "trade diversion" and will be welfare worsening if $\left(\alpha_{11}-\alpha_{21}\right) / D>0$. A gains from the preferential terms of trade offered by $B$ if the trade pattern is $A-B-C$. This term will disappear if the partner countries compensate each other for these losses in tariff revenue due to trade diversion.

The effect of induced changes in the world terms of trade are captured in the third term. The sign of this will depend upon the change in income in each country and their income elasticities of demand for A's export and import goods.

In the large-countries case, the welfare of $\mathrm{C}$ is also affected by the formation of the club.

$$
\begin{aligned}
e_{u}^{c} d u^{c} & =\frac{1}{D}\left[\alpha_{13} t^{a^{\prime}} s^{a} \Delta^{a}-\alpha_{23} t^{b^{\prime}} s^{b} \Delta^{b}\right] \\
& +\frac{1}{D}\left[\alpha_{13}-\alpha_{23}\right] m_{m}^{a b} \cdot d T \\
& +\frac{1}{D}\left[\alpha_{13} B^{a}+\alpha_{23} B^{b}+\alpha_{33^{B}} B^{c}\right]\left[s^{b} \Delta^{b}-s^{a} \Delta^{a}\right]
\end{aligned}
$$


The third term of this equation, as in equation (38), reflects the effects of changes in the external terms of trade on welfare. The first term captures the impact on the welfare of $\mathrm{C}$ of $\mathrm{A}$ and $\mathrm{B}$ receiving intra-club terms of trade improvements. If $\alpha_{73} / D$ and $\alpha_{23} / D$ are positive, then $C$ benefits from the increased desires for trade of $A$ and $B$ as a result of their forming the club. The second term reports the net effect on $C$ of trade diversion. Within the club, one member country loses tariff revenue, the other receives improved terms of trade; the impact on $C$ will depend on whether or not the club's net trade with $C$ increases. For example, with trade pattern $B-A-C$, if $A$ reduces its import tariff on a good $x, m_{x}^{a b} \cdot d I_{x}<0$. A's trade with $C$ will fall (if $\alpha_{13} / D>0$ ) and $B^{\prime} s$ trade will rise. If $\alpha_{13} / D>\alpha_{23} / D$ then $A^{\prime}$ 's lost revenues will inflict a greater Ioss on C's welfare than could be compensated by B's increased desire for trade. If $\alpha_{73}=\alpha_{23}$, the gain from one country exactly offsets the loss from the other and C's welfare is unaffected. Similarly, a scheme of compensation payments between $A$ and $B$ (to remove the ill-effects of trade diversion on club formation) would nullify the impact on $\mathrm{C}$.

It is clear that a preferential trading club that is mutually beneficial to its members is one that yields the "small countries" benefits of improved intra-club terms of trade (assuming compensation for lost tax revenues) while not inducing sufficiently adverse changes in the extra-club terms of trade.

6. SUMMARY

An attempt has been made to discuss preferential trading agreements in a model sufficiently general to include all patterns of trading. It was assumed throughout that the club formation would not alter the specific pattern of trade and that the only distortions in the wor Id economy were trade taxes and subsidies. ${ }^{13}$ 
Small countries can gain from a preferential trading club only if their domestic exports are net substitutes for goods imported from the partner alone and if their imports are net substitutes for the goods exported only to the partner. Free trade within the club is not necessarily optimal. When the partners are large countries or there are local goods, the benefits of improved intra-club terms of trade will be augmented or diminished dependent on the movements in the world terms of trade. 


\section{Footnotes}

${ }^{*}$ I am indebted to Jim Markusen, John McMillan, and Jim Melvin for helpful comments and criticisms of earlier drafts of this paper: the usual disclaimer applies.

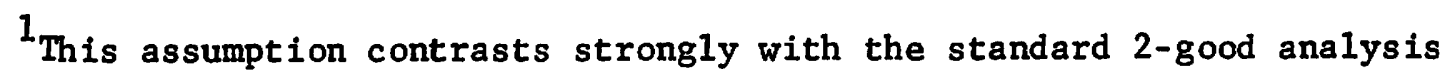
in which a change of the trade pattern is centra1.

2 This was suggested by Corden (1984) and is also studied by Ethier and Horn (1984).

$3_{\text {With more than one household, redistributive measures would have to }}$ be taken so that any benefits from forming a PTC were shared.

4 In a 2-good mode1, A and B import different goods and so a free trade area and a customs union are equivalent [for example, in Negishi (1972)]。

5 This reflects Viner's (1950) distinction between nominal and effective protective duties.

6 There has been a bewildering variety of uses for the term "trade diversion". The use here is intended to be in consonance with the traditional definition: that the tariff reduction redirects trade from the lower-cost to the higher-cost country with the consequent loss of tariff revenue.

${ }^{7}$ This was pointed out by Kemp (1969, p. 31)。

8 obviously A and B's optimal taxes on A-C-B trade would be zero as they are both small with respect to the country with which they trade.

${ }^{9}$ This terminology was coined by Lipsey (1970, p. 36).

${ }^{10}$ McMillan and McCann (1981), in their model with complete specialization, showed that, under particular circumstances, the second-best optimum tariff can be negative. This would imply subsidization of intra-club trade. 
${ }^{11}$ This is consistent with Collier's (1979) "ideal level of aggregation". ${ }^{12}$ A1though Ethier and Horn (1984) do consider local goods, they seem to ignore the induced changes in their relative prices.

${ }^{13}$ Wonnacott and Wonnacott (1981) discuss the benefits from customs union formation under the circumstances of both a change in the pattern of trade and in the presence of transport costs. 


\section{References}

Berglas, E. (1979). "Preferential Trading Theory: The n Commodity Case." Journal of Political Economy, vol. 87 (Apri1), pp. 315-32. (1983). "The Case for Unilateral Tariff Reductions : Foreign Tariffs Rediscovered." American Economic Review, vol. 73 (December), pp. 1141-42. Chacholiades, M. (1978). International Trade Theory and Policy. New York: McGraw-Hi11.

Collier, P. (1979). "The Welfare Effects of Customs Unions: An Anatomy." Economic Journal, vol. 89 (March), pp. 84-95.

Corden, W. M. (1976). "Customs Union Theory and the Nonuniformity of Tariffs." Journal of International Economics, vol. 6 (February), pp. 99-100. (1984). "The Normative Theory of International Trade," in R. W. Jones and P. B. Kenen (editors), Handbook of International Economics, vol. 1. Amsterdam: North-Holland.

Dixit, A. K. and Norman, V. (1980). Theory of International Trade. Welwyn: James Nisbet.

Ethier, W. and Horn, H. (1984). "A New Look at Economic Integration," in H. Kierzkowski (editor), Monopolistic Competition in International Trade. London: Oxford University Press.

Kemp, M. C. (1969)。 A Contribution to the General Equilibrium Theory of Preferential Trading. Amsterdam: North-Holland. and Wan, H. (1976). "An Elementary Proposition Concerning the Formation of Customs Unions," in M. C. Kemp, Three Topics in the Theory of International Trade. Amsterdam: North-Holland.

Iipsey, R. G. (1970)。 The Theory of Customs Unions: A General Equilibrium Analysis. Iondon: Weidenfeld and Nicolson. 
Lloyd, P. J. (1974). "3×3 Theory of Customs Unions." Journal of International Economics, vol. 12 (February), pp. 41-63.

McMillan, J. and McCann, E. (1981). "Welfare Effects in Customs Unions." Economic Journal, vol. 91 (September), pp. 697-703.

Meade, J. E. (1955). The Theory of Customs Unions. Amsterdam: North-Holland. Melvin, J. R. (1969). "Comments on the Theory of Customs Unions." Manchester School, vol. 36 (June), pp. 161-8。

Mundell, R. A. (1964). "Tariff Preferences and the Terms of Trade." Manchester School of Economic and Social Studies, Jamuary, pp. 1-13. Reprinted in R. A. Mundell (1968), International Economics. London: Collier-Macmillan, pp. 54-64.

Negishi, T. (1972). General Equilibrium Theory and International Trade. Amsterdam: North-Holland.

Petith, H. C. (1977). "European Integration and the Terms of Trade." Economic Journal, vol. 87 (June), pp. 262-272.

Riezman, R. (1979). "A $3 \times 3$ Model of Customs Unions." Journal of International Economics, vol. 9 (August), pp. 341-54.

Vanek, J. (1965). General Equilibrium of International Discrimination: The Case of Customs Unions. Cambridge, Mass.: Harvard University Press.

Viner, J. (1950). The Customs Union Issue. New York: Carnegie-Endowment for International Peace.

Wonnacott, P. and Wonnacott, R. (1981). "Is Unilateral Tariff Reduction Preferable to a Customs Union? The Curious Case of the Missing Foreign Tariffs." American Economic Review, vol. 71 (September), pp. 704-13. 


\section{Appendix A}

Partition the set of $n$ goods into 6 subsets according to the following

$n_{7}$ : trade pattern A-B-C, B exports goods

$\mathrm{n}_{2}$ : trade pattern $A-B-C, B$ imports goods

$\mathrm{n}_{3}$ : trade pattern $B-A-C, A$ exports goods

$\mathrm{n}_{4}:$ trade pattern B-A-C, A imports goods

$\mathrm{n}_{5}$ : trade pattern $A-C-B, C$ exports goods

$\mathrm{n}_{6}:$ trade pattern A-C-B, C imports goods.

In this case, making similar partitions,

$$
\begin{aligned}
& \Delta_{1}^{a}=\mathrm{dt}_{1}^{\mathrm{ai}}-\mathrm{dt}_{1}^{\mathrm{bi}}<0 \text {, i.e., all elements negative } \\
& \Delta_{2}^{a}=d t_{2}^{a i}-d t_{2}^{b i}>0 \\
& \Delta_{k}^{a}=0, k=3,4,5,6
\end{aligned}
$$

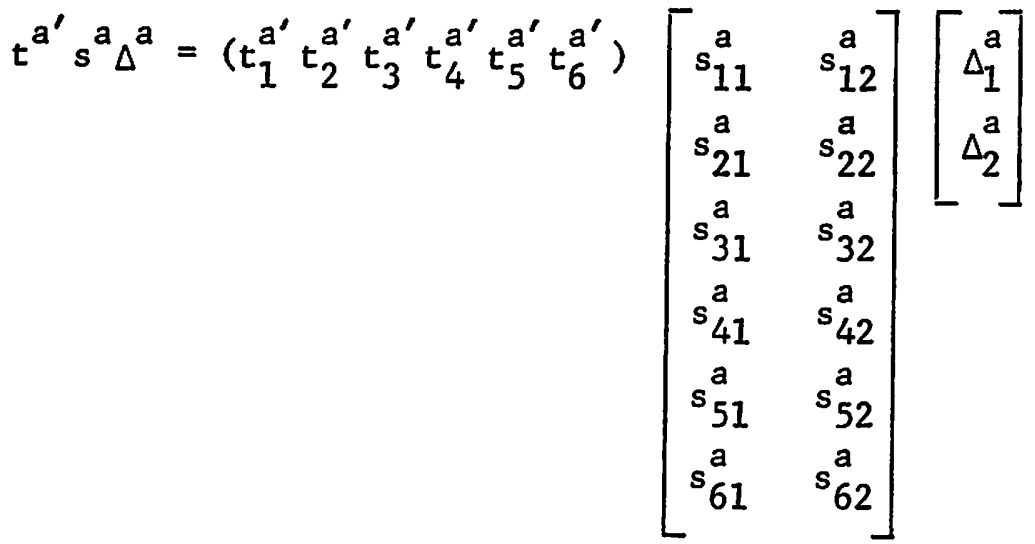

Assume, for simplicity, that A's import tariffs are all the same proportion of the domestic prices and that export taxes are also a common proportion of domestic prices

$$
\begin{aligned}
\text { i.e., import tariff, } t_{k}^{a} & =\tau^{a} p_{k}^{a}, k=1,4,5, \tau^{a}>0 \\
\text { export tax, } \quad t_{k}^{a} & =-\sigma^{a} p_{k}^{a}, k=2,3,6, \sigma^{a}>0
\end{aligned}
$$

Then, 


$$
\begin{aligned}
t^{a^{\prime}} s^{a} \Delta^{a} & =\tau^{a}\left\{p_{1}^{a^{\prime}} s_{11}^{a}+p_{4}^{a^{\prime}} s_{41}^{a}+p_{5}^{a^{\prime}} s_{51}^{a}\right\} \Delta_{1}^{a}-\sigma^{a}\left\{p_{2}^{a^{\prime}} s_{21}^{a}+p_{3}^{a^{\prime}} s_{31}^{a}+p_{6}^{a^{\prime}} s_{61}^{a}\right\} \Delta_{1}^{a} \\
& +\tau^{a}\left\{p_{1}^{a^{\prime}} s_{12}^{a}+p_{4}^{a^{\prime}} s_{42}^{a}+p_{5}^{a^{\prime}} s_{52}^{a}\right\} \Delta_{2}^{a}-\sigma^{a}\left\{p_{2}^{a^{\prime}} s_{22}^{a}+p_{3}^{a^{\prime}} s_{32}^{a}+p_{6}^{a^{\prime}} s_{62}^{a}\right\} \Delta_{2}^{a}
\end{aligned}
$$

From equation $(10), s^{a} p^{a}=0 \Rightarrow p^{a^{\prime}} s^{a^{\prime}}=0, s^{a}$ is symmetric and so $p^{a^{\prime}} s^{a}=0$. Thus

$$
p_{1}^{a^{\prime}} s_{1 j}^{a}+p_{2}^{a^{\prime}} s_{2 j}^{a}+p_{3}^{a^{\prime}} s_{3 j}^{a}+p_{4}^{a^{\prime}} s_{4 j}^{a}+p_{5}^{a^{\prime}} s_{5 j}^{a}+p_{6}^{a^{\prime}} s_{6 j}^{a}=0
$$

for $j=1, \ldots, 6$.

Substituting into (A2)

$$
t^{a^{\prime}} s^{a} \Delta^{a}=-\left(\tau^{a}+\sigma^{a}\right)\left(p_{2}^{a^{\prime}} s_{21}^{a}+p_{3}^{a^{\prime}} s_{31}^{a}+p_{6}^{a^{\prime}} s_{61}^{a}\right) \Delta_{1}^{a}+\left(\tau^{a}+\sigma^{a}\right)\left(p_{1}^{a^{\prime}} s_{12}^{a}+p_{4}^{a^{\prime}} s_{42}^{a}+p_{5}^{a^{\prime}} s_{52}^{a}\right) \Delta_{2}^{a}
$$

For a welfare gain from changes in the terms of trade, need

$$
\left(p_{2}^{a^{\prime}} s_{21}^{a}+p_{3}^{a^{\prime}} s_{31}^{a}+p_{6}^{a^{\prime}} s_{61}^{a}\right) \Delta_{1}^{a}-\left(p_{1}^{a^{\prime}} s_{12}^{a}+p_{4}^{a^{\prime}} s_{42}^{a}+p_{5}^{a^{\prime}} s_{52}^{a}\right) \Delta_{2}^{a}<0
$$

This requires that at least one of the bracketed expressions to be positive, i.e., that either or both of the following conditions holds:

(i) A's exports to $B$, that are facing improved world prices due to the PTC, are substitutes in consumption and production for A's imports.

(ii) A's imports from $B$, that have falling domestic prices due to the PTC, are substitutes in consumption and production for A's exports. 


\section{Appendix B}

The optimal import taxes, $\hat{t}_{1}^{a}$, will maximize the terms of trade benefits. That is, from equation (A1)

$$
\left\{\hat{t}_{1}^{a^{\prime}} s_{11}^{a}+t_{2}^{a^{\prime}} s_{21}^{a}+t_{3}^{a^{\prime}} s_{31}^{a}+t_{4}^{a^{\prime}} s_{41}^{a}+t_{5}^{a^{\prime}} s_{51}^{a}+t_{6}^{a^{\prime}} s_{61}^{a}\right\} \Delta_{1}^{a}=0
$$

Suppose, as before for simplicity, that import tariffs and export taxes on other goods are uniform. Then

$$
\left\{\left(\hat{t}_{1}^{a^{\prime}}-\tau p_{1}^{a^{\prime}}\right) s_{11}^{a}+\tau^{a}\left(p_{1}^{a^{\prime}} s_{11}^{a}+p_{4}^{a^{\prime}} s_{41}^{a}+p_{5}^{a^{\prime}} s_{51}^{a}\right)-\sigma^{a}\left(p_{2}^{a^{\prime}} s_{21}^{a}+p_{3}^{a^{\prime}} s_{31}^{a}+p_{6}^{a^{\prime}} s_{61}^{a}\right)\right\} \Delta_{1}^{a}=0
$$

Substituting equation (A3) into this

$$
\left(\hat{t}_{1}^{a^{\prime}}-\tau^{a} p_{1}^{a^{\prime}}\right) s_{11}^{a} \Delta_{1}^{a}-\left(\tau^{a}+\sigma^{a}\right)\left(p_{2}^{a^{\prime}} s_{21}^{a}+p_{3}^{a^{\prime}} s_{3.1}^{a}+p_{6}^{a^{\prime}} s_{61}^{a}\right) \Delta_{1}^{a}=0
$$

For a welfare improvement, the last expression must be negative [see Appendix A] and so

$$
\left(\hat{t}_{1}^{a^{\prime}}-\tau^{a} p_{1}^{a^{\prime}}\right) s_{11}^{a} \Delta_{1}^{a}<0
$$

The optimal tariff must be (proportionately) less than the tariff on other imports, but is not necessarily zero or, indeed, positive. 